\title{
Therapeutic Impact of Deep Balloon-assisted Small Bowel Enteroscopy on Red Blood Cell Transfusion
}

\author{
Amandeep S. Kalra' Andrew J. Walker ${ }^{2}$ \\ Mehak Misha ${ }^{4}$ Deepak V. Gopal ${ }^{1}$ \\ 1Division of Gastroenterology and Hepatology, Department of \\ Medicine, School of Medicine and Public Health, University of \\ Wisconsin, Madison, Wisconsin, United States \\ 2SSM Health System-Dean Medical Group, Madison, Wisconsin, \\ United States \\ ${ }^{3}$ Division of Gastroenterology and Hepatology, School of Medicine \\ and Public Health, University of Wisconsin, Gl Associates - Aurora \\ St. Luke's Medical Center, Milwaukee, Wisconsin, United States \\ ${ }^{4}$ Gundersen Hospitals and Clinics, La Crosse, Wisconsin, \\ United States
}

J Digest Endosc:2020;11:258-262

\begin{abstract}
Address for correspondence Deepak V. Gopal, MD, FRCP(C), FACP, AGAF, FASGE, FACG, MRCP (London), Division of Gastroenterology and Hepatology, Department of Medicine, School of Medicine and Public Health, University of Wisconsin, 1685 Highland Avenue, MFCB 4223, Madison, WI 53705, United States (e-mail:dvg@medicine.wisc.edu).
\end{abstract}

\author{
Abstract \\ Keywords \\ - DBE-double-balloon \\ enteroscopy \\ - OGIB-obscure gastro- \\ intestinal bleeding \\ - red blood transfusion \\ - therapeutic \\ endoscopy
}

Objective Evaluate impact of balloon-assisted deep small bowel enteroscopy on red blood cell transfusion requirement in patients with obscure gastrointestinal (GI) bleeding.

Methods Retrospective study of patients, who underwent balloon-assisted deep enteroscopy with double-balloon enteroscopy (DBE) at two tertiary care academic centers (University of Wisconsin and Aurora St. Luke's Medical Center) over a 55-month consecutive period. Sixty-nine patients with reliable blood transfusion records were identified during this time period. DBE was preceded by small bowel capsule endoscopy (CE) within 1 year in 38 cases. Transfusion requirements 6 months prior and postintervention were measured to see if DBE had any impact on the need for blood transfusions.

Results Sixty-nine patients ( 25 females and 44 males) were included. Mean age \pm standard deviation (SD) was $63 \pm 17$ years. Wilcoxon signed rank test statistics were used to find the difference in the rate of blood transfusion. There was a statistically significant decrease in rate of packed red blood cell (pRBC) transfusion post DBE and endoscopic therapy with coagulation $(p<0.001)$. Argon plasma coagulation was used to ablate all arteriovenous malformations (AVMs) except in one (subepithelial lesion). Those that required $>5$ units pRBC transfusions pre-DBE had the most benefit.

Conclusions Our study demonstrates that transfusion requirements are significantly reduced in those undergoing therapy with DBE and coagulation for obscure GI bleed.
DOI https://doi.org/

$10.1055 / \mathrm{s}-0040-1721552$

ISSN 0976-5042. (c) 2020. Society of Gastrointestinal Endoscopy of India.

This is an open access article published by Thieme under the terms of the Creative Commons Attribution-NonDerivative-NonCommercial-License, permitting copying and reproduction so long as the original work is given appropriate credit. Contents may not be used for commercial purposes, or adapted, remixed, transformed or built upon. (https://creativecommons.org/licenses/by-nc-nd/4.0/). Thieme Medical and Scientific Publishers Pvt. Ltd. A-12, 2nd Floor, Sector 2, Noida-201301 UP, India 


\section{Introduction}

Obscure gastrointestinal bleeding (OGIB) is defined as a bleeding in the gastrointestinal (GI) tract without a source identified with repeated GI evaluations and often requires multiple transfusions of packed red blood cells (pRBCs)..$^{1-4}$ As much as $75 \%$ of the total OGIB is due to small bowel lesions. ${ }^{5,6,7}$ Double-balloon enteroscopy (DBE) not only has a diagnostic potential but, due to its therapeutic potential, also has the ability to alter outcomes. ${ }^{8,9}$ However, there is a paucity of data regarding the clinical impact of therapeutic DBE. To evaluate the impact of therapeutic DBE on red blood cell (RBC) transfusion requirement in patients with obscure GI bleeding, we conducted a retrospective study at two tertiary care centers in Wisconsin. Both of our centers utilized DBE (Fujifilm Medical Systems Inc. USA-Endoscopy, Wayne, New Jersey USA) as the primary method of balloon-assisted deep small bowel enteroscopy.

\section{Methods}

\section{Patients}

Data, from a prospective cohort database at two tertiary care medical centers, was retrospectively analyzed on patients who underwent DBE procedure for indication, endoscopic findings, therapeutic intervention, immediate complications, and RBC transfusion units over a 55-month consecutive time period. A total of $211 \mathrm{DBE}$ procedures were performed during this time period, with 163 (77\%) performed for the indication of OGIB; 142 antegrade DBE procedures, and 21 retrograde DBE. A total of 69 DBE patient cases (42\%) had reliable blood transfusion records, of which 61/69 (87\%) were antegrade DBE. This is due to the fact that the two centers are referral centers for DBE, and transfusion records were not available in all cases from outside referring institutions. They all underwent diagnostic or therapeutic intervention with DBE. When available, we also obtained small bowel capsule endoscopy (CE) findings on those patients. Institutional Review Boards at both University of Wisconsin and Aurora St. Luke's Medical Center approved the study. Informed consent was taken for DBE. In certain cases, CE result was obtained from outside hospital and only report was available, and in other cases, patients were referred directly for DBE, given the high index of suspicion for active, obscure overt small bowel bleeding.

DBE was performed either anterograde or retrograde or both, based on the indication and results of $\mathrm{CE}$, when available, to assist with approximation of location of small bowel lesion, distance of insertion, and route of access. All DBEs were performed under general anesthesia; for retrograde DBE, patients underwent bowel preparation the night before the procedure. Diagnostic biopsies or therapeutic procedures were performed as appropriate. The site of most distal advancement was tattooed. DBE was performed by four different experienced interventional endoscopists (DVG, MEB, AS, and NMG).

\section{Results}

A total of 69 patients were included in this study. The mean age \pm standard deviation (SD) was $63 \pm 17$. There were
$36.2 \%$ (25) females and 63.80\% (44) males. All patients had DBE evaluation for obscure GI bleeding as the primary diagnosis with 23/60 (38.3\%) presenting with active overt GI bleeding; additional secondary indications included iron deficiency anemia, abdominal pain, weight loss, and diarrhea ( - Table $\mathbf{1}$ ). A total of 61 cases were per oral antegrade DBE, with mean insertion time of 78.6 minutes to maximum depth of insertion to region of proximal-to-mid ileum (range $180-240 \mathrm{~cm}$ distal to ligament of Treitz), and overall average procedure duration (insertion and withdrawal) of $95.2 \mathrm{~min}-$ utes. The remaining eight cases were per colon retrograde DBE, with mean insertion time of 62.6 minutes to the distal ileum, total procedure duration of 74.6 minutes, and maximum point of insertion into distal ileum approximately 110 to $120 \mathrm{~cm}$ proximal to the ileocecal (IC) valve.

All patients referred for DBE had prior negative upper oesophagogastroduodenscopy (OGD) and colonoscopy, which did not demonstrate source of GI bleeding. Tagged RBC scan was done in $8.7 \%$ of the patients all presenting with active overt OGIB. CE reports were available only in $55 \%$ patients, with findings as described in - Table 2. CE data was not available in all patients, because some patients either went directly to DBE due to active bleeding or had CE done at other facility. DBE was done in all patients, with findings described in - Table $\mathbf{3}$. Of the 20 cases reported as normal, $15 / 20$ had per oral DBE advanced to region of

Table 1 Indications (primary $+/$ - secondary) in DBE for OGIB

\begin{tabular}{|l|l|l|}
\hline $\begin{array}{l}\text { OGIB (overt \& occult + secondary) } \\
\text { indication } \\
\text { Total }\end{array}$ & $\begin{array}{l}\text { Number } \\
69\end{array}$ & $\begin{array}{l}\text { \%age } \\
100\end{array}$ \\
\hline Primary overt OGIB & 23 & 33.30 \\
\hline Iron deficiency anemia & 22 & 31.90 \\
\hline Abdominal pain & 18 & 26.10 \\
\hline Weight loss & 3 & 4.30 \\
\hline Other etiology & 2 & 2.90 \\
\hline Diarrhea & 1 & 1.40 \\
\hline
\end{tabular}

Abbreviations: DBE, double-balloon enteroscopy; OGIB, obscure gastrointestinal bleeding.

Table 2 Capsule endoscopy findings

\begin{tabular}{|c|c|c|}
\hline CE & Number & $\%$ age \\
\hline AVMs & 18 & 26.10 \\
\hline Normal & 8 & 11.60 \\
\hline Other & 5 & 7.20 \\
\hline Polyp/SMT/mass & 4 & 5.80 \\
\hline Stricture & 2 & 2.90 \\
\hline Ulcer & 1 & 1.40 \\
\hline Data unavailable & 31 & 44.90 \\
\hline Total & 69 & 100.00 \\
\hline
\end{tabular}

Abbreviations: AVM, arteriovenous malformation; CE, capsule endoscopy; DBE, double-balloon enteroscopy; SMT, submucosal tumor.

${ }^{2} \mathrm{CE}$ data was not available in all patients because some patients either went directly to DBE due to active bleeding or had CE done at other facility. 
Table 3 OGIB pathology findings on DBE

\begin{tabular}{|l|l|l|}
\hline Findings & Number & \%age \\
\hline AVMs & 22 & 31.9 \\
\hline Normal & 20 & 29.0 \\
\hline Other: & 15 & 21.7 \\
\hline $\begin{array}{l}\text { - Crohn's IBD jejunum \&/or } \\
\text { proximal Ileum }\end{array}$ & 3 & \\
\hline - Crohn's IBD distal ileum & 4 & \\
\hline $\begin{array}{l}\text { - Celiac disease: ulcerative/erosive } \\
\text { jejunal-ileitis }\end{array}$ & 4 & \\
\hline $\begin{array}{l}\text { - Celiac disease/gluten enteropathy } \\
\text { - Mid-distal jejunal GIST }\end{array}$ & 4 & 7.2 \\
\hline $\begin{array}{l}\text { SMT/polyp/mass } \\
\text { lymphoma/adenocarcinoma }\end{array}$ & 5 & 1.4 \\
\hline Ulcer & $3(1$ each) & \\
\hline $\begin{array}{l}\text { - NSAID } \\
\text { - Jejunal Dieulafoy bleed }\end{array}$ & 4 & 5.8 \\
\hline $\begin{array}{l}\text { Ulcerated midileum ischemic/ } \\
\text { inflammatory stricture }\end{array}$ & 3 & 100.0 \\
\hline Small bowel diverticular bleed & 2 & \\
\hline Total & 69 & \\
\hline
\end{tabular}

Abbreviations: AVM, arteriovenous malformation; DBE, double-balloon enteroscopy; GIST, gastrointestinal stromal tumor; IBD, inflammatory bowel disease; NSAID, nonsteroidal anti-inflammatory drug.

Table 4 Comparison of blood transfusion rates

\begin{tabular}{|c|c|c|c|c|}
\hline $\begin{array}{l}\text { Blood transfusion } \\
\text { required }\end{array}$ & $\begin{array}{l}6 \text { months } \\
\text { pre-DBE }\end{array}$ & $\begin{array}{l}6 \text { months } \\
\text { post DBE }\end{array}$ & $Z$ value $^{a}$ & $p$ value ${ }^{*}$ \\
\hline 0 & 39 (56.5\%) & 57 (82.6\%) & \multirow[t]{5}{*}{4.594} & \multirow[t]{5}{*}{$<0.001^{* *}$} \\
\hline $1-5$ & $14(20.3 \%)$ & 11 (15.9\%) & & \\
\hline $6-10$ & 11 (15.9\%) & $1(1.4 \%)$ & & \\
\hline$>10$ & $5(7.2 \%)$ & - & & \\
\hline Total & 69 & 69 & & \\
\hline
\end{tabular}

Abbreviations: DBE, double-balloon enteroscopy.

aWilcoxon signed rank test.

${ }^{*} p<0.05$; significant.

${ }^{* *} p<0.001$.

proximal/mid ileum at maximum point of insertion with tattoo placed, three were retrograde to distal ileum, and two had bidirectional balloon-assisted deep enteroscopy (i.e., retrograde DBE after antegrade DBE demonstrated normal findings). The 20 normal cases had small bowel biopsies performed, which were also within normal limits.

Therapeutic intervention was done in all arteriovenous malformation (AVM) patients except one where AVM was subendothelial. The intervention consisted of hemostasis with argon plasma coagulation (APC) and/or hemoclips. In five patients, polypectomy was performed. Blood transfusion rates were calculated 6 months before and after DBE as described in - Table 4 . Wilcoxon signed rank test statistics

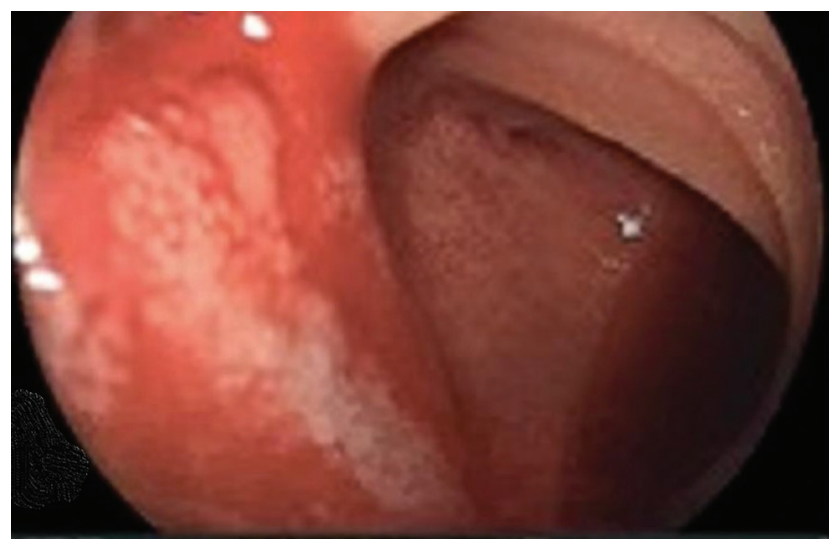

Fig. 166 years/o female with overt obscure gastrointestinal bleeding (OGIB) presenting with hematochezia. Retrograde double-balloon enteroscopy (DBE) showing active bleeding ulcers in distal ileum.

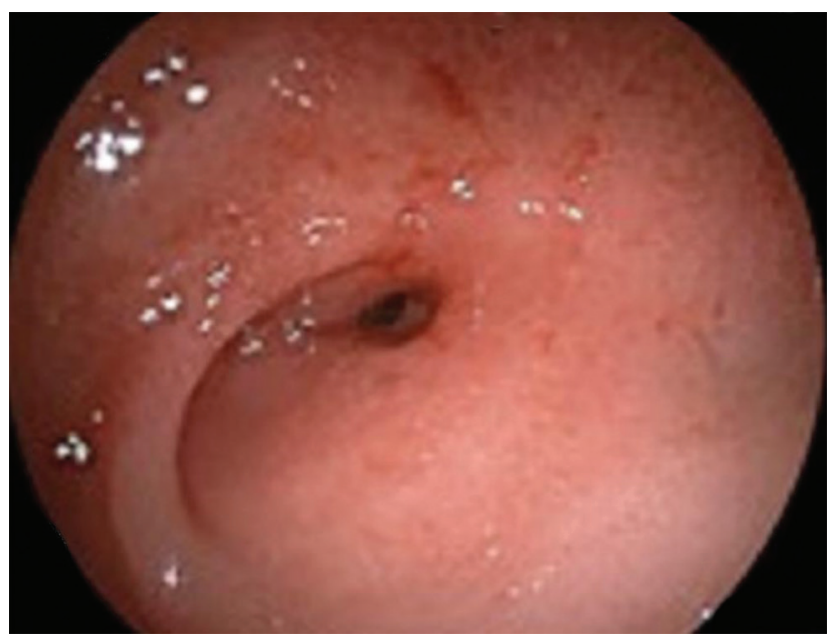

Fig. 246 years/o male with occult obscure gastrointestinal bleeding (OGIB). Double-balloon enteroscopy (DBE), demonstrating ischemic ulcerated stricture in midileum.

was used to find the difference in the rate of blood transfusion, which showed statistically significant decrease in rate of blood transfusion with a $p$ value of $<0.001$. We further looked in subcategories of ulcer (-Figs. 1 and 2), AVMs (-Fig. 3) and submucosal tumor (SMT)/polyp/mass (-Figs. 4 and 5 ) and found that rate of transfusion was significantly reduced in patients with AVMs, but not in those with ulcer or SMT/polyp/mass, as described in - Table 5.

Of the 15 reported as "other" DBE pathology findings, 7 had endoscopic and histopathology features of erosion and superficial mucosal ulceration consistent with small intestinal inflammatory bowel disease (Crohn's distal ileum in 4, and jejunal/proximal ileum Crohn's in 3), 4 had ulcerative/erosive jejunoileitis in celiac disease without histologic features of small bowel lymphoma, and 4 had celiac disease with patchy endoscopic pattern of scalloped mucosa and subtotal villous atrophy without erosions or ulceration. There were no immediate or delayed complications of DBE reported in this study. 


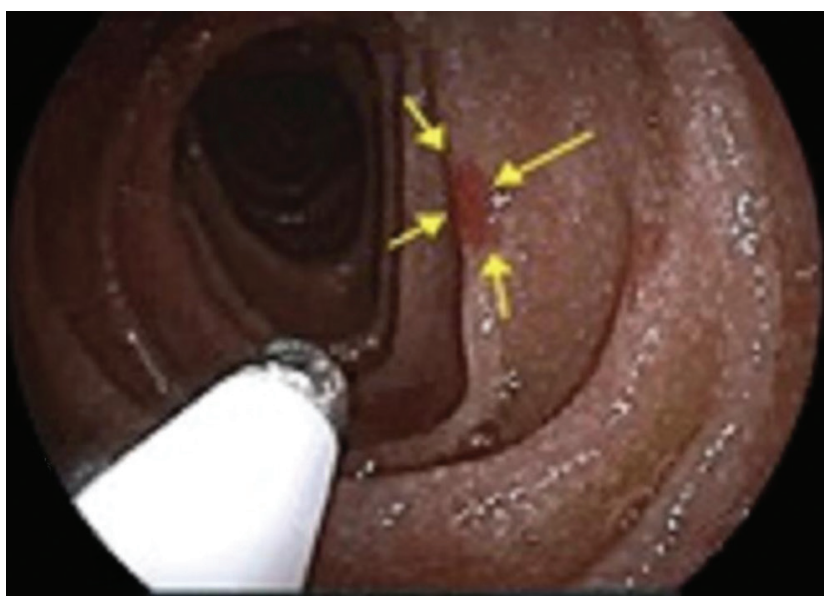

Fig. 369 years/o male with overt obscure gastrointestinal bleeding (OGIB). Antegrade double-balloon enteroscopy (DBE), demonstrating arteriovenous malformation (AVM) in distal jejunum, which is treated with cautery.

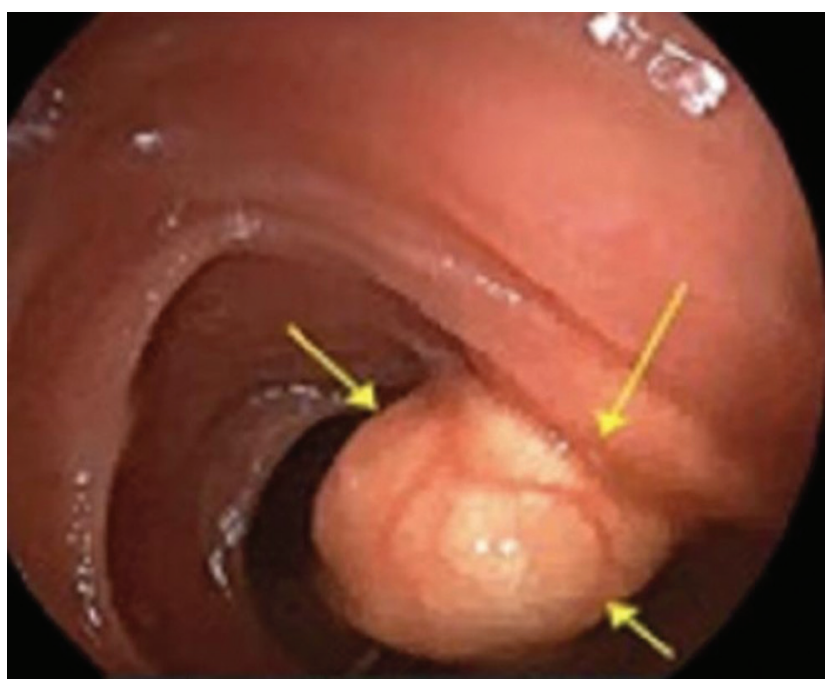

Fig. 446 years/o male with obscure gastrointestinal bleeding (OGIB) and chronic iron deficiency anemia. Antegrade double-balloon enteroscopy (DBE), demonstrating submucosal tumor (SMT) in the distal jejunum.

\section{Discussion}

In this study, we found statistically significant reduction in the requirement of blood transfusion after DBE ( $81.8 \%$ vs. $31.8 \%$ ), due to therapeutic impact of DBE. Blood transfusion requirements decreased significantly in those patients with small bowel AVMs and those that needed $>5$ pRBC transfusions prior to the procedure. Our findings confirm the therapeutic benefit found in other similar studies, whereby coagulation or mechanical hemostasis of AVMs results in decreased rebleeding and transfusion requirements. ${ }^{6,10-13}$

Although our data confirm some of the outcomes reported in other studies, our data is unique since it mimics the "real-world" experience where DBE was performed by multiple endoscopists, and followed-up patients postprocedure for at least 6 months for assessment of outcomes. ${ }^{14-16}$

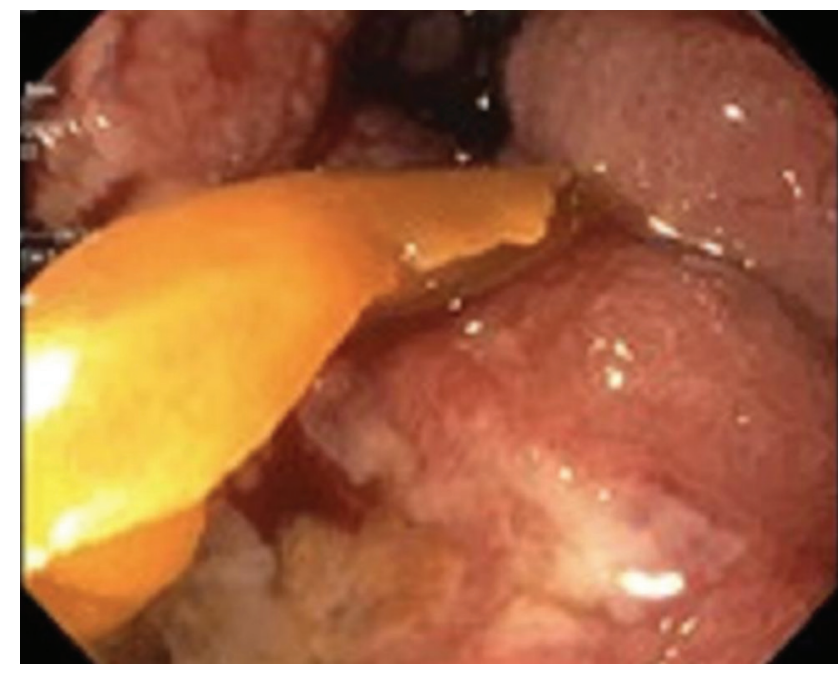

Fig. 581 years/o male with iron deficiency anemia and chronic obscure gastrointestinal bleeding (OGIB). Antegrade double-balloon enteroscopy (DBE) with distal jejunal mass, which is consistent with biopsy-proven small bowel adenocarcinoma.

Table 5 Comparison of blood transfusion required before and after 6 months in patients with AVMs

\begin{tabular}{|l|l|l|l|l|l|}
\hline Findings & $\begin{array}{l}\text { Blood } \\
\text { transfusion } \\
\text { required }\end{array}$ & $\begin{array}{l}\text { Before 6 } \\
\text { months }\end{array}$ & $\begin{array}{l}\text { After 6 } \\
\text { months }\end{array}$ & Z value & $p$ value* \\
\hline \multirow{4}{*}{ AVMs } & 0 & $4(18.2 \%)$ & $15(68.2 \%)$ & 3.508 & $<0.001^{* *}$ \\
\cline { 2 - 4 } & $1-5$ & $9(40.9 \%)$ & $7(31.8 \%)$ & & \\
\cline { 2 - 4 } & $6-10$ & $7(31.8 \%)$ & - & & \\
\cline { 2 - 4 } & $>10$ & $2(9.1 \%)$ & - & \\
\cline { 2 - 4 } & Total & 22 & 22 & & \\
\hline
\end{tabular}

Abbreviation: AVM, arteriovenous malformation.

ailcoxon signed rank test $=$ NS: $p>0.05$; not significant.

${ }^{*} p<0.05$; significant.

${ }^{* *} p<0.001$; highly significant.

In our current study, we found that rate of transfusion was significantly reduced in patients with AVMs as opposed to ulcers and SMT/polyps. While CE studies were only done in $55 \%$ of cases, the source of GI bleed traced to AVMS was likely picked up by $C E$, and DBE was performed with therapeutic intent to perform APC hemostatic therapy. As treatment of AVMS anywhere in GI tract is likely to respond to coagulation therapy (i.e., APC), it is expected that successful hemostasis would prevent recurrence of GI bleeding and future requirement of blood transfusion should reduce significantly postintervention. ${ }^{17}$ DBE appears to have a durable clinical impact on patient care as demonstrated by the reduced $\mathrm{RBC}$ transfusion requirement of patients up to at least 6 months following the procedure.

It is interesting to note that DBE was normal in $29 \%$ of cases when performed for evaluation of OGIB. Normal DBE and negative therapeutic intervention was described in another earlier study, which noted that DBE had no diagnostic yield in $44 \%$ of cases and no therapeutic intervention performed in $55 \%$ of cases. That retrospective case-control study of 55 DBE cases had higher negative diagnostic yield 
and lower therapeutic rate compared with our study but similarly noted that AVMs accounted for the majority of the DBE pathology findings. The authors suggested that factors such as fewer blood transfusion requirements, absence of AVMs or ulcers and, possibly, endoscopist fatigue maybe predictors of negative diagnostic and therapeutic yield of DBE. ${ }^{18}$ The other factors such as extent of DBE insertion, average procedure duration, as well as diverse array of small bowel pathological lesions detected on DBE are similar to other published studies. ${ }^{19-21}$

The main limitation of our study is it is a retrospective analysis of data and has a relatively small sample size. This is in part was due to the pRBC transfusion data which was available only in $42 \%$ of patients undergoing DBE for OGIB. Moreover, small bowel CE findings were also unavailable in $45 \%$ of cases.

Nevertheless, our study demonstrates that DBE is a safe procedure that can be employed to evaluate OGIB. Additionally, DBE has a durable clinical impact on patient care as demonstrated by reduced RBC transfusion requirements of patients up to 6 months following the procedure. Additional prospective, multicenter studies should be designed to further investigate this relationship and assess outcomes on need for hospitalizations or disease-specific mortality.

\section{Conflicts of Interest}

Dr. Guda reports personal fees and other from Boston Scientific, outside the submitted work.

\section{References}

1 Laine L, Sahota A, Shah A. Does capsule endoscopy improve outcomes in obscure gastrointestinal bleeding? Randomized trial versus dedicated small bowel radiography. Gastroenterology 2010;138(5):1673-1680.e1, quiz e11-e12

2 Liu K, Kaffes AJ. Review article: the diagnosis and investigation of obscure gastrointestinal bleeding. Aliment Pharmacol Ther 2011;34(4):416-423

3 Goenka MK, Majumder S, Kumar S, Sethy PK, Goenka U. Single center experience of capsule endoscopy in patients with obscure gastrointestinal bleeding. World J Gastroenterol 2011;17(6):774-778

4 Kaffes AJ, Siah C, Koo JH. Clinical outcomes after double-balloon enteroscopy in patients with obscure GI bleeding and a positive capsule endoscopy. Gastrointest Endosc 2007;66(2):304-309

5 Raju GS, Gerson L, Das A, Lewis B; American Gastroenterological Association. American Gastroenterological Association (AGA) Institute technical review on obscure gastrointestinal bleeding. Gastroenterology 2007;133(5):1697-1717

6 Gerson LB, Batenic MA, Newsom SL, Ross A, Semrad CE. Longterm outcomes after double-balloon enteroscopy for obscure gastrointestinal bleeding. Clin Gastroenterol Hepatol 2009; 7(6):664-669
7 Lee NM, Eisen GM. 10 years of capsule endoscopy: an update. Expert Rev Gastroenterol Hepatol 2010;4(4):503-512

8 Cooley DM, Walker AJ, Gopal DV. From capsule endoscopy to balloon-assisted deep enteroscopy: exploring small-bowel endoscopic imaging. Gastroenterol Hepatol (N Y) 2015;11(3): 143-154

9 Yamamoto H, Sekine Y, Sato Y, et al. Total enteroscopy with a nonsurgical steerable double-balloon method. Gastrointest Endosc 2001;53(2):216-220

10 May A, Friesing-Sosnik T, Manner H, Pohl J, Ell C. Long-term outcome after argon plasma coagulation of small-bowel lesions using double-balloon enteroscopy in patients with mid-gastrointestinal bleeding. Endoscopy 2011;43(9):759-765

11 Sun B, Rajan E, Cheng S, et al. Diagnostic yield and therapeutic impact of double-balloon enteroscopy in a large cohort of patients with obscure gastrointestinal bleeding. Am J Gastroenterol 2006;101(9):2011-2015

12 Madisch A, Schmolders J, Brückner S, Aust D, Miehlke S. Less favorable clinical outcome after diagnostic and interventional double balloon enteroscopy in patients with suspected small-bowel bleeding? Endoscopy 2008;40(9):731-734

13 Shinozaki S, Yamamoto H, Yano T, et al. Long-term outcome of patients with obscure gastrointestinal bleeding investigated by double-balloon endoscopy. Clin Gastroenterol Hepatol 2010;8(2):151-158

14 Kalra AS, Walker AJ, Benson ME, et al. Comparison of capsule endoscopy findings to subsequent double balloon enteroscopy: a dual center experience. Diagn Ther Endosc 2015; 2015:438757

15 Prabakaran P, Guda N, Thomas J, et al. Clinical approach to obscure GI bleeding-Diagnostic testing and management. J Digestive Endoscopy 2013;4(3):61

16 Brito HP, Ribeiro IB, de Moura DTH, et al. Video capsule endoscopy vs double-balloon enteroscopy in the diagnosis of small bowel bleeding: A systematic review and meta-analysis. World J Gastrointest Endosc 2018;10(12):400-421

17 Park JJ, Cheon JH, Kim HM, et al. Negative capsule endoscopy without subsequent enteroscopy does not predict lower long-term rebleeding rates in patients with obscure GI bleeding. Gastrointest Endosc 2010;71(6):990-997

18 Hussan H, Crews NR, Geremakis CM, Bahna S, LaBundy JL, Hachem C. Predictors of double balloon endoscopy outcomes in the evaluation of gastrointestinal bleeding. World $\mathrm{J}$ Gastrointest Endosc 2014;6(6):248-253

19 Su MY, Lin WP, Chiu CT. Experience of double balloon enteroscopy. J Chin Med Assoc 2018;81(3):225-229

$20 \mathrm{Wu}$ CR, Huang LY, Song B, Yi LZ, Cui J. Application of double-balloon enteroscopy in the diagnosis and therapy of small intestinal diseases. Chin Med J (Engl) 2007;120(23): 2075-2080

21 Cazzato IA, Cammarota G, Nista EC, et al. Diagnostic and therapeutic impact of double-balloon enteroscopy (DBE) in a series of 100 patients with suspected small bowel diseases. Dig Liver Dis 2007;39(5):483-487 